\title{
Usual folic acid intakes: a modelling exercise assessing changes in the amount of folic acid in foods and supplements, National Health and Nutrition Examination Survey, 2003-2008
}

\author{
Sarah C Tinker ${ }^{1, *}$, Mary E Cogswell ${ }^{2}$, Heather $C$ Hamner $^{1}$ and Robert J Berry ${ }^{1}$ \\ ${ }^{1}$ National Center on Birth Defects and Developmental Disabilities, Centers for Disease Control and Prevention \\ (CDC), Mail-Stop E86, 1600 Clifton Road, Atlanta, GA 30333, USA: ${ }^{2}$ National Center for Chronic Disease \\ Prevention and Health Promotion, CDC, Atlanta, GA, USA
}

Submitted 29 September 2011: Accepted 20 January 2012: First published online 29 March 2012

\begin{abstract}
Objective: The USA currently fortifies enriched cereal grain products (ECGP) with folic acid at $140 \mu \mathrm{g} / 100 \mathrm{~g}$. In addition, folic acid can be voluntarily added to ready-to-eat cereals (RTEC) up to $400 \mu \mathrm{g} / \mathrm{serving}$ and it is found in many dietary supplements, most often at a dose of $400 \mu \mathrm{g}$. We sought to model folic acid intake under various fortification and supplementation scenarios.

Design: The National Health and Nutrition Examination Survey is a populationbased cross-sectional survey representative of the non-institutionalized, civilian US population. Information on folic acid intake is collected in two $24 \mathrm{~h}$ dietary recalls and survey questions on dietary supplement use, which allows estimation of usual total folic acid intake. We modelled five different levels of folic acid fortification in ECGP, while varying the amounts in RTEC and dietary supplements. Setting: United States.

Subjects: US adults ( $n$ 14353) aged $\geq 19$ years; non-pregnant women of childbearing age ( $n$ 4272).

Results: The percentage of adults with usual daily folic acid intake above the tolerable upper intake level of $1000 \mu \mathrm{g}$ was influenced more by the typical amount in supplements, while the median intake was influenced more by the ECGP fortification level. By manipulating the amount in at least two sources, it was possible to shift the distribution such that more women of childbearing age consumed the recommended intake of $400 \mu \mathrm{g}$ of folic acid without increasing the percentage of adults with intake above the tolerable upper intake level. The results varied among population subgroups.

Conclusions: Our results suggest that combined strategies are required to meet population recommendations for folic acid intake.
\end{abstract}

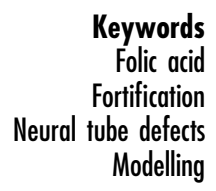

Folic acid

Fortification

Modelling
Randomized controlled trials have established the efficacy of periconceptional folic acid use to prevent neural tube defects (NTD), serious birth defects of the brain and spine $^{(1,2)}$. In 1992, the US Public Health Service (USPHS) recommended that all women capable of becoming pregnant consume at least $400 \mu \mathrm{g}$ of folic acid daily to reduce the risk of having a pregnancy affected by an NTD $^{(3)}$. In 1993, the US Food and Drug Administration (FDA) reviewed the evidence available regarding folic acid and the prevention of NTD, and determined that fortifying the food supply was the most effective way to provide folic acid to all women of childbearing age ${ }^{(4)}$. FDA mandated that by 1998 all enriched cereal grain products (ECGP) be fortified with $140 \mu \mathrm{g}$ of folic acid per
$100 \mathrm{~g}$ of flour ${ }^{(5)}$. In 1998, the Institute of Medicine (IOM) recommended that all women of childbearing potential consume at least $400 \mu \mathrm{g}$ of folic acid from fortified foods and supplements daily, in addition to a diet high in folaterich foods. The IOM set the tolerable upper intake level (UL) of usual folic acid intake from fortified foods and supplements at $1000 \mu \mathrm{g} / \mathrm{d}$ to ensure that usual folic acid intake would not mask signs of anaemia and thereby delay diagnosis of vitamin $\mathrm{B}_{12}$ deficiency, which could lead to irreversible neurological damage ${ }^{(6)}$. Since fortification, it is estimated that the prevalence of NTD in the USA has dropped by $27 \%{ }^{(7)}$.

The USA was not alone in implementing a folic acid fortification policy. Canada mandated in 1998 that all 
ECGP be fortified with $150 \mu \mathrm{g}$ of folic acid per $100 \mathrm{~g}$ of flour $^{(8)}$. Costa Rica implemented wheat and corn flour fortification at $180 \mu \mathrm{g} / 100 \mathrm{~g}$ as well as fortification of milk and rice in $1998^{(9)}$. In 2000 , Chile decided to fortify bread flour at $220 \mu \mathrm{g} / 100 \mathrm{~g}^{(10)}$. South Africa implemented mandatory fortification at $150 \mu \mathrm{g} / 100 \mathrm{~g}$ for wheat flour and $180 \mu \mathrm{g} / 100 \mathrm{~g}$ for maize flour in $2003^{(11)}$. In 2009, Australia began mandatory fortification at $200 \mu \mathrm{g} / 100 \mathrm{~g}$ of the final flour product ${ }^{(12)}$. Voluntarily fortified foods are available in many other countries, including the UK, Ireland and New Zealand.

The methods available for modelling the impact of folic acid fortification have improved since the US fortification policy was established. With the availability of improved data on the folic acid content of foods ${ }^{(13)}$, the use of measurement error models ${ }^{(14)}$ and better reporting of supplement intake, more accurate estimates of usual folic acid intake are now possible. The modelling exercise reported in the present paper provides a framework to evaluate different options of folic acid fortification and supplementation levels for countries worldwide.

\section{Methods}

\section{National Health and Nutrition Examination Survey}

The National Health and Nutrition Examination Survey (NHANES) is a complex, multistage survey designed to be representative of the US civilian, non-institutionalized population. It includes extensive, in-person interviews and a physical examination. NHANES is conducted in two-year cycles by the National Center for Health Statistics (NCHS) at the US Centers for Disease Control and Prevention (CDC). We used data from the 2003-2004, 2005-2006 and 2007-2008 cycles. All study participants provided informed consent, and the study protocol received approval from the NCHS Ethical Review Board. The methods of the survey are described in detail elsewhere ${ }^{(15-17)}$. The nutrition data used for the present analysis were collected in a household interview and two $24 \mathrm{~h}$ dietary recalls. The first recall was administered in person at the time of the physical examination and the second recall was administered 3 to $10 \mathrm{~d}$ later via telephone.

The NHANES data sets contain nutrient information for every food reported by each participant in the two $24 \mathrm{~h}$ dietary recalls, including folic acid. A daily total intake for each nutrient for each participant is also included in the data sets, which is a sum of the nutrient amounts from each individual food reported by that participant on that day. Food codes were assigned to each reported food, which allowed us to identify ready-to-eat cereals (RTEC; codes available upon request). RTEC and meal replacement products (MRP) are the only food sources of folic acid other than ECGP in the USA; MRP contribute only a minor amount to total folic acid intake in our data.
For each participant, the amount of folic acid consumed from RTEC and MRP was defined as the sum of the folic acid intake from all reported foods identified as RTEC and MRP, respectively, consumed in the previous $24 \mathrm{~h}$. We then estimated the amount of folic acid consumed from ECGP by subtracting the folic acid intake consumed from RTEC and MRP from the total folic acid intake from all foods consumed.

We obtained data on dietary supplement use during the household interview from questions in which the participants were asked whether they took a dietary supplement in the last $30 \mathrm{~d}$ and if so, how often they took the supplement and to show the supplement package to the interviewer. NCHS then obtained product information regarding the ingredients, amounts and serving sizes of the reported supplements and made these data available. We estimated the average daily amount of folic acid consumed from supplements by multiplying the number of days the participant reported taking the supplement over the past $30 \mathrm{~d}$ times the folic acid dose in one serving times the daily number he/she reported consuming (e.g. 2 tablets), divided by the amount in one serving (serving size, e.g. 2 tablets), times 30: i.e. (days taken in the last $30 \mathrm{~d} \times$ nutrient dose per serving $\times$ number of supplements taken $) \div($ serving size $\times 30)$. We estimated the total folic acid consumed daily from all sources for each participant by adding the daily average folic acid from supplements to the total folic acid from foods on each day of the dietary recall. We considered anyone who reported consuming a supplement containing folic acid within the past $30 \mathrm{~d}$ to be a supplement user.

There were 16665 adults aged 19 years and older in the 2003-2008 NHANES. We excluded 2312 participants based on: being pregnant at the time of the survey ( $n$ 658), not attending the mobile examination centre ( $n$ 728), having incomplete data for the day 1 ( $n 835)$ or day $2(n 76)$ dietary recall, or having missing data on supplement use ( $n$ 15). Among the 5424 women of childbearing age (15 to 44 years; partial overlap with adult age range), exclusions were made for pregnancy ( $n$ 730), not attending the mobile examination centre ( $n$ 151), unreliable day 1 ( $n$ 251) or day 2 ( $n$ 15) dietary recall data, and missing dietary supplement ( $n$ 5) data.

\section{Simulation scenarios}

We varied the level of folic acid used in mandatory ECGP fortification, voluntary RTEC fortification and supplements (Table 1) for each individual in the populations we considered, regardless of their sources of folic acid consumed. If an individual did not consume folic acid from one of the sources then the modelled level of that source for that individual would not impact their estimate of folic acid intake. We included the daily intake of folic acid from MRP in the estimates of individuals' total daily folic acid intake, but left the level unchanged in the models. We assessed five levels for mandatory ECGP 
Table 1 Folic acid fortification and supplementation scenarios considered in simulation analyses

\begin{tabular}{|c|c|c|c|}
\hline Scenario & $\mathrm{ECGP}^{*}$ & RTEC + & Supplement‡ \\
\hline A70 & 70 & 400 & 400 \\
\hline A140 & 140 & 400 & 400 \\
\hline A210 & 210 & 400 & 400 \\
\hline A280 & 280 & 400 & 400 \\
\hline A350 & 350 & 400 & 400 \\
\hline B70 & 70 & 200 & 400 \\
\hline B140 & 140 & 200 & 400 \\
\hline B210 & 210 & 200 & 400 \\
\hline B280 & 280 & 200 & 400 \\
\hline B350 & 350 & 200 & 400 \\
\hline C70 & 70 & 100 & 400 \\
\hline C140 & 140 & 100 & 400 \\
\hline C210 & 210 & 100 & 400 \\
\hline C280 & 280 & 100 & 400 \\
\hline C350 & 350 & 100 & 400 \\
\hline D70 & 70 & 400 & 200 \\
\hline D140 & 140 & 400 & 200 \\
\hline D210 & 210 & 400 & 200 \\
\hline D280 & 280 & 400 & 200 \\
\hline D350 & 350 & 400 & 200 \\
\hline E70 & 70 & 200 & 200 \\
\hline E140 & 140 & 200 & 200 \\
\hline E210 & 210 & 200 & 200 \\
\hline E280 & 280 & 200 & 200 \\
\hline E350 & 350 & 200 & 200 \\
\hline F70 & 70 & 100 & 200 \\
\hline F140 & 140 & 100 & 200 \\
\hline F210 & 210 & 100 & 200 \\
\hline F280 & 280 & 100 & 200 \\
\hline F350 & 350 & 100 & 200 \\
\hline G70 & 70 & 0 & 0 \\
\hline G140 & 140 & 0 & 0 \\
\hline G210 & 210 & 0 & 0 \\
\hline G280 & 280 & 0 & 0 \\
\hline G350 & 350 & 0 & 0 \\
\hline
\end{tabular}

ECGP, enriched cereal grain product; RTEC, ready-to-eat cereal. ${ }^{*} \mathrm{ECGP}$, level of mandatory folic acid fortification $(\mu \mathrm{g} / 100 \mathrm{~g})$. tRTEC, maximum allowable amount of folic acid ( $\mu \mathrm{g} / \mathrm{serving}$ ).

$\ddagger$ Supplement, usual amount of folic acid in a dietary supplement ( $\mu \mathrm{g} / \mathrm{dose})$.

fortification: multiples of $70 \mu \mathrm{g}$, from $70 \mu \mathrm{g}$ to $350 \mu \mathrm{g} /$ $100 \mathrm{~g}$ flour, which include the levels considered during the development of the current folic acid fortification legislation in the USA ${ }^{(4)}$. We assessed four levels for the upper limit of folic acid per serving of RTEC: $400 \mu \mathrm{g}$ (the current limit ${ }^{(18)}$ ), $200 \mu \mathrm{g}, 100 \mu \mathrm{g}$ (a limit considered by FDA in $1993^{(4)}$ ) and no folic acid in RTEC. We did not model any changes to RTEC that did not contain folic acid (i.e. those cereals without folic acid in the current scenario had no folic acid in any of the modelled scenarios). We also assessed the most common amount of folic acid in dietary supplements at $400 \mu \mathrm{g}, 200 \mu \mathrm{g}$ and no folic acid in supplements. In total, we evaluated thirty-five scenarios.

\section{Modelling sources of folic acid}

\section{Enriched cereal grain products}

For each participant, we varied the amount of folic acid consumed from ECGP by multiplying his/her daily ECGP folic acid intake under the existing US scenario of $140 \mu \mathrm{g} / 100 \mathrm{~g}$ flour by a factor. The factor was calculated by dividing the ECGP fortification level for each scenario $(70,140,210,280,350 \mu \mathrm{g})$ by $140 \mu \mathrm{g} / 100 \mathrm{~g}$ (factor $=0 \cdot 5$, $1 \cdot 0,1 \cdot 5,2 \cdot 0$ and $2 \cdot 5$, respectively).

\section{Ready-to-eat cereals}

Folic acid fortification of RTEC in the USA is not required, and the amount of folic acid added to RTEC varies by brand; many are not fortified with folic acid. The current US regulation regarding the upper limit for voluntary fortification is based on serving size ${ }^{(18)}$, which also varies among brands. We used the US Department of Agriculture's Food and Nutrient Database for Dietary Studies (FNDDS), which contains information on the weight of one cup of each brand of RTEC and the folic acid content of $100 \mathrm{~g}$ of each brand of RTEC ${ }^{(19,20)}$. The FNDDS database was linked to NHANES data using a standard food code. Information on serving size was not available in NHANES or FNDDS; we obtained serving size information from manufacturer and other websites (available upon request).

Using the serving size in cups of each RTEC, the weight (g) of a cup of each RTEC and the folic acid content of $100 \mathrm{~g}$ of each RTEC, we calculated the folic acid content of one serving of each RTEC.

If the per-serving content of the RTEC, which could be up to $400 \mu \mathrm{g} / \mathrm{serving}$, was below the upper limit of the modelled scenario $(0,100,200 \mu \mathrm{g} / \mathrm{serving})$, the folic acid intake from that RTEC was left unchanged. If the per-serving content of the RTEC was above the upper limit of a given modelled scenario, the per-serving content was forced to equal that limit. In the latter case, amounts for folic acid consumed from that RTEC in the modelled scenarios were adjusted by multiplying by a proportional factor calculated as (modelled per-serving content $) \div$ (actual per-serving content).

\section{Supplements}

The most commonly observed amount included in the dietary supplements reported by the participants in NHANES 2003-2008 was $400 \mu \mathrm{g}$ of folic acid (data not shown). We considered scenarios in which the amount of folic acid in supplements equalling $400 \mu \mathrm{g}$ was changed to $200 \mu \mathrm{g}$. In addition, we considered scenarios in which there was no folic acid intake from supplements.

\section{Analysis}

For descriptive analyses we used the SUDAAN statistical software package version 10 (2008; RTI, Research Triangle Park, NC, USA) to account for the complex survey design. We used the Software for Intake Distribution Estimation (PC-SIDE) version 1.02 (2003; Iowa State University, Ames, IA, USA) ${ }^{(21)}$ to estimate the distribution of folic acid intake accounting for both between- and within-person variability in intake. We used the estimated distribution to quantify the median and interquartile range (IQR) of daily usual folic acid intake, the percentage of women of childbearing age who achieved the recommended daily usual folic acid intake of $400 \mu \mathrm{g}$ or more and the percentage of adults with 
daily usual folic acid intake exceeding the UL of $1000 \mu \mathrm{g}^{(6)}$ for each of the scenarios listed in Table 1. We accounted for the NHANES complex sampling design in PC-SIDE using ninety-two jack-knife replicate weights based on the 6-year combined sampling weights for the first day of dietary recall provided for NHANES, which account for differential non-response and non-coverage and adjust for designed oversampling. We adjusted for day of week of the dietary recall and interview method (in person or by telephone). We also conducted stratified analyses by race and ethnicity. We used $\chi^{2}$ tests to identify differences in estimated intake from the current scenario.

\section{Results}

We analysed data on 14353 adults and 4272 women of childbearing age (Table 2). Approximately a third of adults reported consuming RTEC containing folic acid (30.4\%, 95\% CI 28.8\%, 32·1\%); RTEC consumption was more common among non-Hispanic white (NHW) adults, women and older adults (Table 2). Among women of childbearing age, $31.7 \%$ reported consumption of RTEC containing folic acid (95\% CI 28.9\%, 34.6\%), and consumption was more often reported by NHW and Mexican Americans (MA) than non-Hispanic blacks (NHB). Use of supplements containing folic acid was reported by $37 \cdot 8 \%$ of adults (95\% CI 35.9\%, 39.8\%) and 31.4\% of women of childbearing age (95\% CI $28 \cdot 7 \%, 34 \cdot 2 \%)$. For adults and women of childbearing age, significantly more NHW reported use of supplements containing folic acid than did NHB or MA (Table 2). Use of supplements containing folic acid was more common among female adults and older adults compared with male adults and younger adults, respectively.

\section{Median intake}

Under the current US scenario (A140) the median daily usual folic acid intake among women of childbearing age was $238 \mu \mathrm{g}$ (IQR: $143 \mu \mathrm{g}, 383 \mu \mathrm{g}$ ) and for US adults was $275 \mu \mathrm{g}$ (IQR: $154 \mu \mathrm{g}, 457 \mu \mathrm{g}$ ). As we increased the level of folic acid in ECGP within each scenario (A-G), the modelled median intake of folic acid also increased (Table 3). For example, under scenario A350, in which we increased the mandatory fortification level of ECGP to $350 \mu \mathrm{g} / 100 \mathrm{~g}$ and did not change the amount of folic acid in RTEC and supplements, the median usual intake of folic acid for women of childbearing age was estimated at $435 \mu \mathrm{g}$ (IQR: $302 \mu \mathrm{g}, 602 \mu \mathrm{g}$ ) and for adults at $490 \mu \mathrm{g}$ (IQR: $332 \mu \mathrm{g}, 683 \mu \mathrm{g}$ ). The only scenarios for which at least $50 \%$ of women of childbearing age had daily usual folic acid intake above the recommended $400 \mu \mathrm{g}$ were those in which ECGP were fortified at $350 \mu \mathrm{g} / 100 \mathrm{~g}$ (A350, B350, C350 and D350).

The median usual daily folic acid intake was influenced more by changing the ECGP fortification level than by changing the typical amount in supplements or the maximum allowable level of RTEC fortification (Fig. 1; Supplementary materials). As an example, halving the ECGP fortification level relative to the current scenario (A140 to A70) resulted in an approximately 30\% reduction in the median daily usual folic acid intake (from $238 \mu \mathrm{g}$ to $164 \mu \mathrm{g}$ ) among women of childbearing age, the target population for this public health intervention. By contrast, when we halved both the typical supplement dose and the maximum allowable fortification level for RTEC (E140) the median daily usual folic acid intake among this group was reduced by only $11 \%$ (from $238 \mu \mathrm{g}$ to $212 \mu \mathrm{g}$ ).

\section{Impact on percentage of adults with intake above the tolerable upper intake level}

The proportion of adults with usual folic acid intake above the UL was influenced most by changing the typical folic acid supplement dose, followed by the level of ECGP fortification, and least by the maximum allowable level of RTEC fortification (Fig. 2; Supplementary materials). For example, compared with the current scenario, halving the typical supplement dose (D140) resulted in a $63 \%$ decrease in the percentage of adults with usual daily folic acid intake above the UL (from $2 \cdot 4 \%$ to $0.9 \%$ ). Halving the ECGP fortification level (A70) decreased the percentage of adults with usual intake exceeding the UL by $21 \%$ (from $2 \cdot 4 \%$ to $1 \cdot 9 \%$ ). When the maximum allowable level of RTEC fortification was halved (B140) the percentage of adults with daily usual folic acid intake exceeding the UL decreased by $17 \%$ (from $2 \cdot 4 \%$ to $2 \cdot 0 \%$ ).

\section{Distribution of intake}

The current population distribution of daily usual folic acid intake in the USA is such that $23.0 \%$ of women of childbearing age achieve the recommended level of intake and $2 \cdot 4 \%$ of adults have intake that exceeds the UL (Supplementary materials). Under the A scenarios, in which only the level of folic acid in ECGP was modified, these two levels decreased or increased together.

As shown in Fig. 3 (and Supplementary materials), at least two sources of folic acid need to be changed, relative to the current US scenario, to increase the percentage of women of childbearing age who achieve the recommended intake, while lowering or not changing the percentage of all adults with intake exceeding the UL. To illustrate, scenario C210, in which the level of folic acid in ECGP was raised to $210 \mu \mathrm{g} / 100 \mathrm{~g}$ and in RTEC was limited to $100 \mu \mathrm{g} /$ serving, resulted in no change in the percentage of adults with intake exceeding the UL and a statistically significant $5.5 \%$ absolute increase in women of childbearing age who achieve the recommended intake. The results from the simulation of scenarios B210, D210, D280, E280, E350, F280 and F350 also displayed this pattern.

Our results in Fig. 2 (and Supplementary materials) suggest that if ECGP served as the only source of folic acid ( $\mathrm{G}$ scenarios) no adults would have intake exceeding the UL. 
Table 2 Population characteristics and prevalence of reported consumption of RTEC and supplements containing folic acid among US adults (age 19 years and older) and non-pregnant women of childbearing age (15 to 44 years), National Health and Nutrition Examination Survey, 2003-2008

\begin{tabular}{|c|c|c|c|c|c|c|c|c|c|c|c|c|}
\hline & \multicolumn{3}{|c|}{ Total } & \multicolumn{3}{|c|}{ RTEC consumers* } & \multicolumn{3}{|c|}{ Supplement userst } & \multicolumn{3}{|c|}{$\begin{array}{l}\text { RTEC consumers and users of } \\
\text { supplements containing folic acid }\end{array}$} \\
\hline & $n \ddagger$ & Percentage & $95 \% \mathrm{Cl}$ & $n \ddagger$ & Percentage & $95 \% \mathrm{Cl}$ & $n \neq$ & Percentage & $95 \% \mathrm{Cl}$ & $n \ddagger$ & Percentage & $95 \% \mathrm{Cl}$ \\
\hline Adults & 14353 & & & 4207 & $30 \cdot 4$ & $28 \cdot 8,32 \cdot 1$ & 4819 & $37 \cdot 8$ & $35 \cdot 9,39 \cdot 8$ & 1676 & $13 \cdot 5$ & $12 \cdot 3,14 \cdot 7$ \\
\hline \multicolumn{13}{|l|}{ Race/ethnicity } \\
\hline Non-Hispanic white & 7104 & $72 \cdot 2$ & $68 \cdot 1,75 \cdot 9$ & 2486 & $33 \cdot 4$ & $31 \cdot 3,35 \cdot 5 \S, \|$ & 3031 & $42 \cdot 7$ & $40 \cdot 0,45 \cdot 5 \S, \|$ & 1204 & $16 \cdot 1$ & $14 \cdot 6,17 \cdot 9 \S, \|$ \\
\hline Non-Hispanic black & 3102 & $11 \cdot 2$ & $9 \cdot 2,13 \cdot 7$ & 731 & $22 \cdot 4$ & $20 \cdot 1,24 \cdot 8$ & 783 & $23 \cdot 8$ & $21 \cdot 5,26 \cdot 3 \|$ & 191 & $5 \cdot 9$ & $4 \cdot 9,7 \cdot 1$ \\
\hline Mexican American & 2712 & $7 \cdot 9$ & $6 \cdot 3,9 \cdot 9$ & 684 & $25 \cdot 0$ & $21 \cdot 8,28 \cdot 4$ & 600 & $19 \cdot 9$ & $17 \cdot 3,22 \cdot 7$ & 186 & $6 \cdot 2$ & $4 \cdot 9,8 \cdot 0$ \\
\hline \multicolumn{13}{|l|}{ Sex } \\
\hline Female & 7099 & $51 \cdot 4$ & $50 \cdot 5,52 \cdot 3$ & 2194 & $31 \cdot 6$ & $29 \cdot 7,33 \cdot 6$ & 2605 & $41 \cdot 4$ & $39 \cdot 1,43 \cdot 79$ & 925 & $14 \cdot 9$ & $13 \cdot 5,16 \cdot 4$ \\
\hline Male & 7254 & $48 \cdot 6$ & $47 \cdot 7,49 \cdot 5$ & 2013 & $29 \cdot 2$ & $27 \cdot 2,31 \cdot 2$ & 2214 & $34 \cdot 1$ & $32 \cdot 0,36 \cdot 2$ & 751 & $12 \cdot 0$ & $10 \cdot 7,13 \cdot 4$ \\
\hline \multicolumn{13}{|l|}{ Age category } \\
\hline 19-64 years & 10653 & $82 \cdot 7$ & $81 \cdot 5,83 \cdot 8$ & 2827 & $28 \cdot 2$ & $26 \cdot 4,30 \cdot 0^{\star *}$ & 3186 & $35 \cdot 6$ & $33 \cdot 6,37 \cdot 5^{\star *}$ & 983 & $11 \cdot 6$ & $10 \cdot 4,12 \cdot 9^{\star *}$ \\
\hline $65+$ years & 3700 & $17 \cdot 3$ & $16 \cdot 2,18 \cdot 5$ & 1380 & $41 \cdot 1$ & $38 \cdot 5,43 \cdot 8$ & 1633 & $48 \cdot 7$ & $46 \cdot 0,51 \cdot 5$ & 693 & $22 \cdot 2$ & $20 \cdot 2,24 \cdot 4$ \\
\hline $\begin{array}{l}\text { Women of childbearing age } \\
\text { Race/ethnicity }\end{array}$ & \multicolumn{11}{|c|}{ Race/ethnicity } & $9 \cdot 8,13 \cdot 2$ \\
\hline Non-Hispanic white & 1641 & $66 \cdot 8$ & $62 \cdot 2,71 \cdot 2$ & 552 & $33 \cdot 4$ & $29 \cdot 6,37 \cdot 5+t$ & 571 & $36 \cdot 9$ & $32 \cdot 8,41 \cdot 2+t, \ddagger \ddagger$ & 218 & $13 \cdot 4$ & $11 \cdot 0,16 \cdot 4+十$, 㧊 \\
\hline Non-Hispanic black & 1134 & $13 \cdot 2$ & $10 \cdot 8,16 \cdot 1$ & 327 & $25 \cdot 4$ & $21 \cdot 9,29 \cdot 3 \neq \ddagger$ & 205 & $19 \cdot 3$ & $15 \cdot 5,23 \cdot 8$ & 68 & & $\S \S$ \\
\hline Mexican American & 1011 & $10 \cdot 0$ & $8 \cdot 0,12 \cdot 4$ & 341 & $31 \cdot 0$ & $27 \cdot 0,35 \cdot 2$ & 156 & $17 \cdot 4$ & $14 \cdot 4,20 \cdot 9$ & 69 & & $\S \S$ \\
\hline
\end{tabular}

RTEC, ready-to-eat cereal.

All $P$ values are from $\chi^{2}$ tests.

${ }^{*}$ RTEC consumer defined as anyone who reported consumption of an RTEC containing folic acid on either of the two $24 \mathrm{~h}$ dietary recalls.

tSupplement user defined as anyone who reported consuming a supplement containing folic acid in the past $30 \mathrm{~d}$.

fUnweighted.

SSignificantly different from non-Hispanic black adults $(P<0 \cdot 05)$.

IISignificantly different from Mexican American adults $(P<0 \cdot 05)$.

SSignificantly different from males $(P<0.05)$.
${ }^{\star}$ Significantly different from older adults $(P<0.05)$

t+Significantly different from non-Hispanic black women of childbearing age $(P<0.05)$.

¥¥Significantly different from Mexican-American women of childbearing age $(P<0.05)$.

\#+Significantly different from
\$\$D $<12$; estimates unstable. 
Table 3 Median usual daily intake of folic acid among US non-pregnant women of childbearing age (15 to 44 years) and all adults (age 19 years and older) under various fortification and supplementation scenarios, National Health and Nutrition Examination Survey, 2003-2008

\begin{tabular}{|c|c|c|c|c|c|c|c|c|c|}
\hline \multirow[b]{2}{*}{ Scenario } & \multirow[b]{2}{*}{ RTEC $^{*}$} & \multirow[b]{2}{*}{ Supplement† } & \multirow[b]{2}{*}{ ECGP } & \multicolumn{3}{|c|}{ WCBA } & \multicolumn{3}{|c|}{ Adults } \\
\hline & & & & Median intake§ & SE & IQR & Median intake§ & SE & IQR \\
\hline \multicolumn{10}{|c|}{ Changing mandatory ECGP and maximum voluntary RTEC fortification levels (no change to supplement amounts) } \\
\hline A70 & 400 & 400 & 70 & 164 & $3 \cdot 1$ & 88,307 & 189 & $2 \cdot 1$ & 91,386 \\
\hline$A 140$ & 400 & 400 & 140 & 238 & $3 \cdot 6$ & 143,383 & 275 & $2 \cdot 4$ & 154,457 \\
\hline A210 & 400 & 400 & 210 & 306 & $4 \cdot 0$ & 198,459 & 353 & $2 \cdot 7$ & 215,530 \\
\hline A280 & 400 & 400 & 280 & 371 & $4 \cdot 5$ & 250,432 & 423 & $2 \cdot 8$ & 274,606 \\
\hline A350 & 400 & 400 & 350 & 435 & $5 \cdot 0$ & 302,602 & 490 & $3 \cdot 0$ & 332,683 \\
\hline B70 & 200 & 400 & 70 & 157 & $3 \cdot 0$ & 83,294 & 183 & $2 \cdot 0$ & 88,373 \\
\hline B140 & 200 & 400 & 140 & 230 & $3 \cdot 4$ & 138,370 & 268 & $2 \cdot 3$ & 150,445 \\
\hline B210 & 200 & 400 & 210 & 298 & 3.9 & 191,445 & 344 & $2 \cdot 6$ & 210,519 \\
\hline B280 & 200 & 400 & 280 & 363 & $4 \cdot 3$ & 243,518 & 415 & $2 \cdot 7$ & 268,595 \\
\hline B350 & 200 & 400 & 350 & 425 & $4 \cdot 8$ & 295,590 & 482 & $2 \cdot 9$ & 325,671 \\
\hline $\mathrm{C} 70$ & 100 & 400 & 70 & 145 & $2 \cdot 7$ & 77,272 & 168 & $1 \cdot 8$ & 84,352 \\
\hline C140 & 100 & 400 & 140 & 218 & $3 \cdot 2$ & 130,349 & 251 & $2 \cdot 1$ & 142,425 \\
\hline C210 & 100 & 400 & 210 & 285 & $3 \cdot 6$ & 182,426 & 328 & $2 \cdot 4$ & 200,500 \\
\hline C280 & 100 & 400 & 280 & 349 & $4 \cdot 1$ & 234,499 & 399 & $2 \cdot 6$ & 257,576 \\
\hline C350 & 100 & 400 & 350 & 411 & $4 \cdot 6$ & 285,572 & 466 & $2 \cdot 9$ & 314,651 \\
\hline \multicolumn{10}{|c|}{ Changing mandatory ECGP and maximum voluntary RTEC fortification levels and decreasing the usual folic acid amount in dietary } \\
\hline D70 & 400 & 200 & 70 & 149 & $2 \cdot 5$ & 85,253 & 166 & $1 \cdot 6$ & 89,282 \\
\hline D140 & 400 & 200 & 140 & 219 & $2 \cdot 9$ & 140,327 & 242 & $1 \cdot 8$ & 150,362 \\
\hline D210 & 400 & 200 & 210 & 282 & $3 \cdot 4$ & 193,404 & 311 & $2 \cdot 0$ & 209,444 \\
\hline D280 & 400 & 200 & 280 & 343 & 3.9 & 243,477 & 377 & $2 \cdot 3$ & 263,523 \\
\hline D350 & 400 & 200 & 350 & 406 & $4 \cdot 4$ & 292,549 & 443 & $2 \cdot 6$ & 316,603 \\
\hline E70 & 200 & 200 & 70 & 142 & $2 \cdot 4$ & 80,242 & 159 & 1.5 & 85,271 \\
\hline E140 & 200 & 200 & 140 & 212 & $2 \cdot 8$ & 134,315 & 235 & $1 \cdot 7$ & 146,351 \\
\hline E210 & 200 & 200 & 210 & 275 & $3 \cdot 2$ & 186,389 & 303 & 1.9 & 204,431 \\
\hline E280 & 200 & 200 & 280 & 337 & $3 \cdot 7$ & 235,463 & 369 & $2 \cdot 2$ & 257,509 \\
\hline E350 & 200 & 200 & 350 & 398 & $4 \cdot 2$ & 285,535 & 435 & $2 \cdot 5$ & 310,589 \\
\hline F70 & 100 & 200 & 70 & 131 & $2 \cdot 3$ & 73,224 & 146 & $1 \cdot 4$ & 79,252 \\
\hline F140 & 100 & 200 & 140 & 199 & $2 \cdot 6$ & 126, 297 & 221 & 1.5 & 138,331 \\
\hline F210 & 100 & 200 & 210 & 263 & $3 \cdot 1$ & 177,372 & 289 & $1 \cdot 8$ & 195,411 \\
\hline F280 & 100 & 200 & 280 & 324 & 3.5 & 226,445 & 355 & $2 \cdot 1$ & 247,489 \\
\hline \multirow{2}{*}{\multicolumn{10}{|c|}{ Changing mandatory ECGP levels with no folic acid fortification of RTEC and no folic acid from dietary supplements }} \\
\hline & & & & & & & & & \\
\hline G70 & 0 & 0 & 70 & 60 & 0.7 & 47,77 & 64 & 0.4 & 48,84 \\
\hline G140 & 0 & 0 & 140 & 119 & $1 \cdot 3$ & 92,151 & 126 & 0.8 & 95,165 \\
\hline G210 & 0 & 0 & 210 & 178 & $2 \cdot 0$ & 137,224 & 188 & $1 \cdot 2$ & 141,246 \\
\hline G280 & 0 & 0 & 280 & 236 & $2 \cdot 6$ & 183,297 & 250 & $1 \cdot 6$ & 188,326 \\
\hline G350 & 0 & 0 & 350 & 294 & $3 \cdot 2$ & 228,371 & 312 & $2 \cdot 0$ & 234,406 \\
\hline
\end{tabular}

ECGP, enriched cereal grain product; RTEC, ready-to-eat cereal; WCBA, women of childbearing age; IQR, interquartile range.

Italics indicates current fortification/supplementation scenario; see Table 1 for details of others.

${ }^{*}$ RTEC levels indicate the maximum allowable voluntary fortification of RTEC under the given scenario $(\mu \mathrm{g} / \mathrm{serving})$.

tSupplement amounts indicate the usual amount of folic acid in dietary supplements ( $\mu \mathrm{g} / \mathrm{dose})$.

¥ECGP levels indicate the mandatory fortification of ECGP under the given scenario $(\mu \mathrm{g} / 100 \mathrm{~g})$.

$\S \mu \mathrm{g} / \mathrm{d}$.

At ECGP fortification levels less than $210 \mu \mathrm{g} / 100 \mathrm{~g}$ ( $\mathrm{G} 70$ and G140) no women of childbearing age would consume the recommended amount of folic acid. Under the highest level of ECGP fortification modelled, $350 \mu \mathrm{g} / 100 \mathrm{~g}$ (G350), significantly fewer women of childbearing age met the recommended intake than under the current US scenario.

The distribution of daily usual folic acid intake was markedly different among US subpopulations of different races and ethnicities (Table 4). Under the current fortification and supplementation scenario, 29.3\% (95\% CI 26.6\%, $32.0 \%)$ of NHW women of childbearing age achieve the recommended intake of folic acid intake, while only $8.7 \%$ (95\% CI $5 \cdot 2 \%, 12 \cdot 3 \%)$ of $\mathrm{NHB}$ and $12 \cdot 4 \%$ (95\% CI $8 \cdot 6 \%$, $16 \cdot 2 \%)$ of MA women of childbearing age achieve that amount of intake. NHW adults were almost six times more likely to have intake exceeding the UL under the current scenario compared with NHW and MA adults $(3.5 \%, 0 \cdot 6 \%$ and $0.6 \%$, for NHW, NHB and MA, respectively).

The absolute change in the percentage of women of childbearing age who achieve the recommended intake, compared with the current scenario, was generally similar across scenarios for NHW, NHB, and MA. However, the relative percentage change was much higher for NHB and MA than for NHW. As an example, doubling the folic acid in ECGP (A280) increased the percentage of women of childbearing age with recommended intake by an absolute value of $19 \cdot 4 \%, 18 \cdot 7 \%$ and $19 \cdot 7 \%$, and the relative percentage change was an increase of $66 \cdot 2 \%, 214.9 \%$ and $158.9 \%$, for NHW, NHB and MA, respectively. In none of the scenarios examined were more than $50 \%$ 


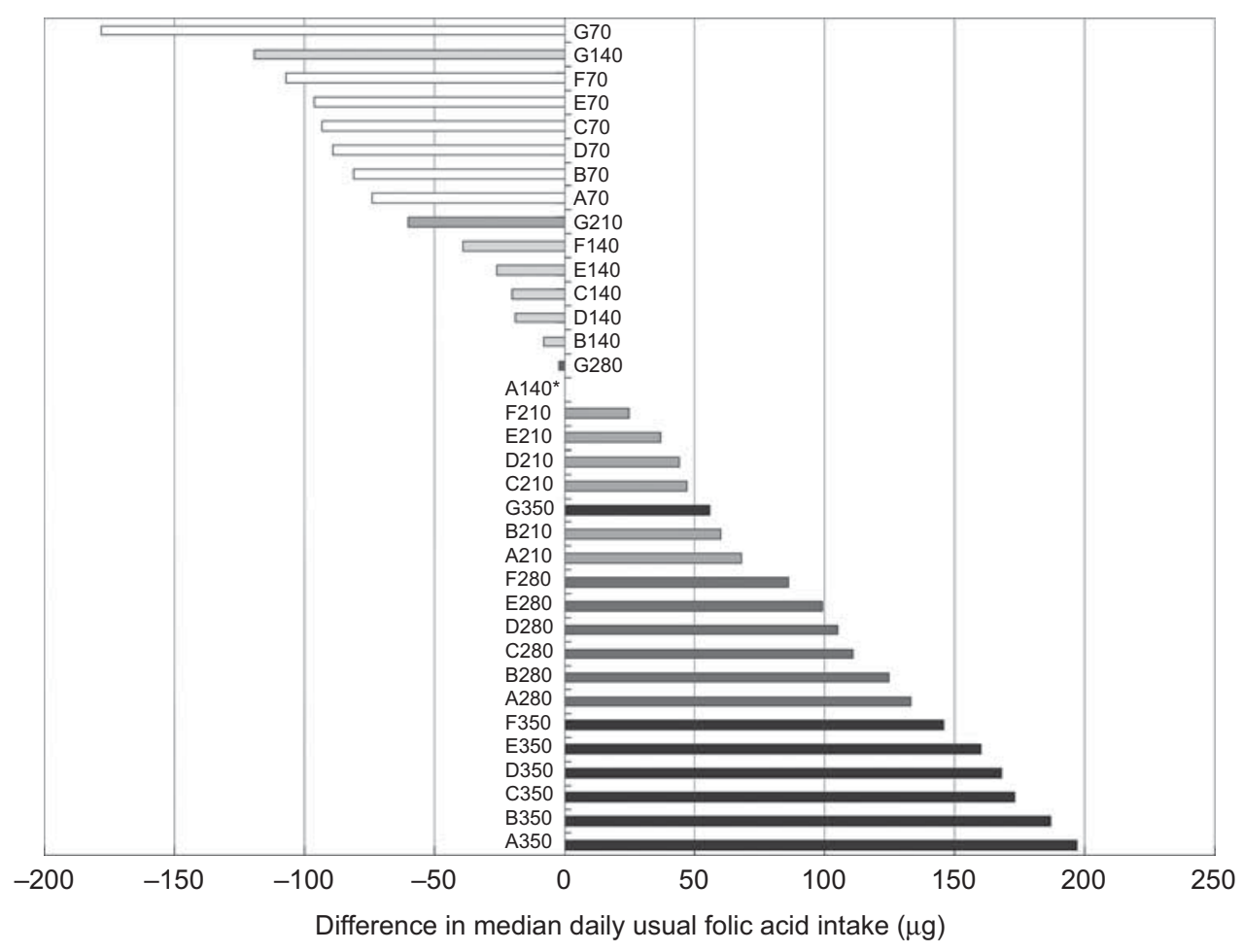

Modelled fortification level of ECGP in $\mu \mathrm{g}$ folic acid/100 $\mu \mathrm{g}$ :

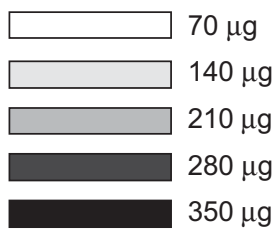

A scenarios: $400 \mu \mathrm{g} / \mathrm{RTEC}$ serving; $400 \mu \mathrm{g}$ usual supplement dose B scenarios: $200 \mu \mathrm{g} / \mathrm{RTEC}$ serving; $400 \mu \mathrm{g}$ usual supplement dose C scenarios: $100 \mu \mathrm{g} / \mathrm{RTEC}$ serving; $400 \mu \mathrm{g}$ usual supplement dose D scenarios: $400 \mu \mathrm{g} / \mathrm{RTEC}$ serving; $200 \mu \mathrm{g}$ usual supplement dose E scenarios: $200 \mu \mathrm{g} / \mathrm{RTEC}$ serving; $200 \mu \mathrm{g}$ usual supplement dose F scenarios: $100 \mu \mathrm{g} / \mathrm{RTEC}$ serving; $200 \mu \mathrm{g}$ usual supplement dose

G scenarios: No folic acid from RTEC or supplements

Fig. 1 Difference in median daily usual folic acid intake $(\mu \mathrm{g})$ from current scenario (A140*), US non-pregnant women of childbearing age (15 to 44 years), National Health and Nutrition Examination Survey, 2003-2008 (ECGP, enriched cereal grain product; RTEC, ready-to-eat cereal)

of NHB or MA women of childbearing age able to achieve the recommended intake. For all scenarios, the relative percentage change for the percentage of adults exceeding the UL was similar for the racial/ethnic groups at the lower ECGP levels and higher for NHB and MA compared with NHW at the higher ECGP levels.

\section{Discussion}

Our results indicate that the distribution of usual intake of folic acid intake among US adults is affected by the levels of both mandatory and voluntary fortification of foods and the typical amount of folic acid in supplements. Assuming the proportion of US adults who use supplements and consume RTEC with folic acid remains constant, modifying the level of folic acid in ECGP would have the greatest impact on increasing the percentage of women of childbearing age who meet the IOM recommendation. In contrast, modifying the typical dose of folic acid in dietary supplements would have the greatest impact on the percentage of adults with usual daily intake exceeding the UL. Taken together these results suggest that, in the USA, usual folic acid intake exceeding the UL 


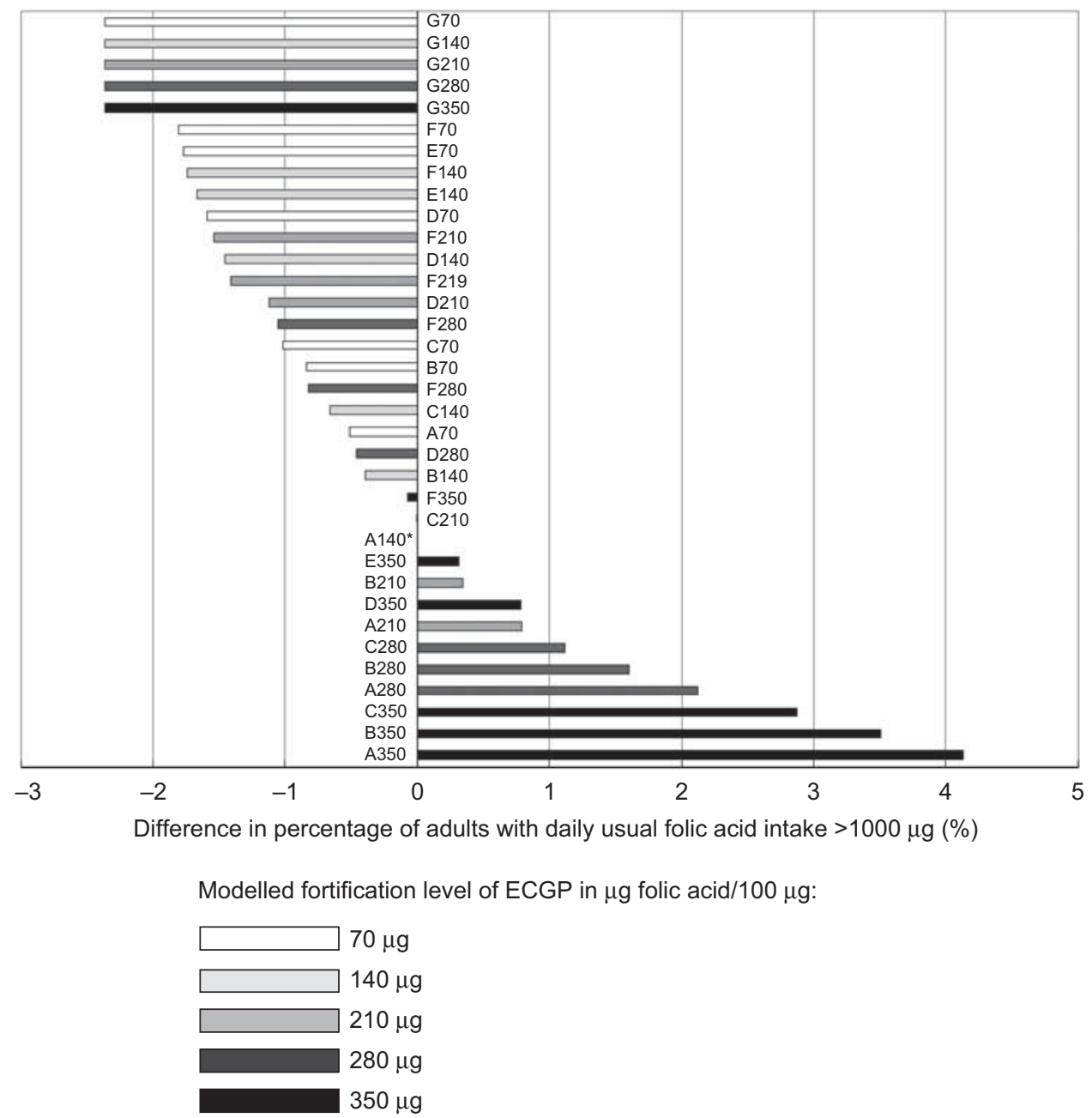

A scenarios: $400 \mu \mathrm{g} / \mathrm{RTEC}$ serving; $400 \mu \mathrm{g}$ usual supplement dose

B scenarios: $200 \mu \mathrm{g} / \mathrm{RTEC}$ serving; $400 \mu \mathrm{g}$ usual supplement dose

C scenarios: $100 \mu \mathrm{g} / \mathrm{RTEC}$ serving; $400 \mu \mathrm{g}$ usual supplement dose

D scenarios: $400 \mu \mathrm{g} / \mathrm{RTEC}$ serving; $200 \mu \mathrm{g}$ usual supplement dose

E scenarios: $200 \mu \mathrm{g} / \mathrm{RTEC}$ serving; $200 \mu \mathrm{g}$ usual supplement dose

F scenarios: $100 \mu \mathrm{g} / \mathrm{RTEC}$ serving; $200 \mu \mathrm{g}$ usual supplement dose

G scenarios: No folic acid from RTEC or supplements

Fig. 2 Difference from current scenario $\left(A 140^{\star}\right)$ in percentage of US adults (age 19 years and older) with daily usual folic acid intake $>1000 \mu \mathrm{g}$, National Health and Nutrition Examination Survey, 2003-2008 (ECGP, enriched cereal grain product; RTEC, ready-to-eat cereal)

is largely a function of the amount of folic acid in supplements. Conversely, more than one strategy is needed to meet the recommendations for folic acid intake among women of childbearing age. Although increasing the level of folic acid in ECGP increases overall intake, it is more effective if a large proportion of US women of childbearing age also consume supplements or RTEC with folic acid.

Our results add to those of modelling exercises prior to fortification ${ }^{(4,22)}$. Direct comparison is difficult as we used updated data and focused on the percentage of women of childbearing age meeting the USPHS ${ }^{(3)}, \mathrm{IOM}^{(6)}$ and US Preventive Services Task Force recommendations $^{\text {(23) }}$ for daily intake of at least $400 \mu \mathrm{g}$ of folic acid, rather than overall folate intake. As in previous stu$\operatorname{dies}^{(4,22)}$, we found that fortification of ECGP would increase total folic acid intake among all consumers across the entire distribution of intakes. Our new finding is that increasing the level of folic acid fortification in ECGP would not substantially increase the percentage of US adults with intake above the UL but could increase the percentage of women meeting recommended folic acid intake. We found that modifying the amount of folic acid in supplements and RTEC influences intake of 


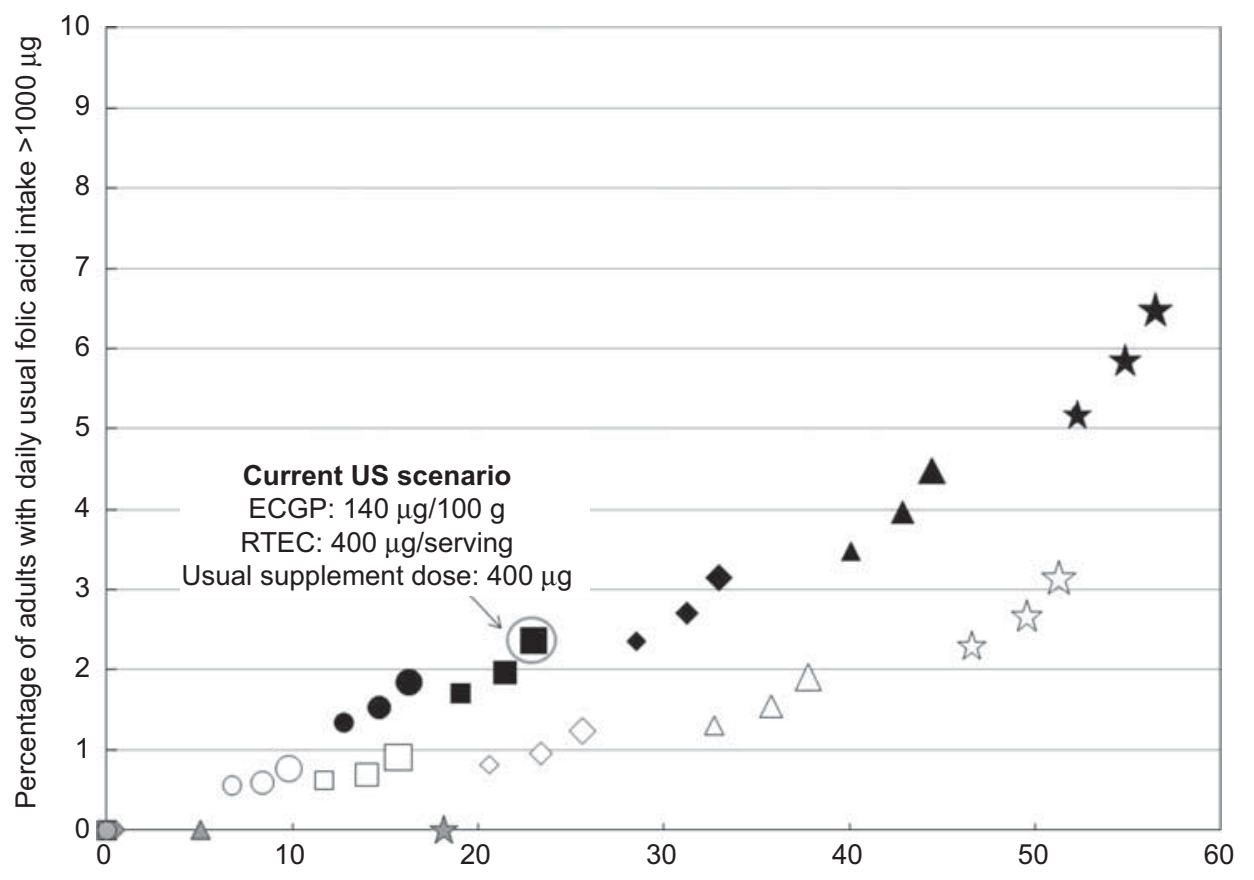

Percentage of non-pregnant women of childbearing age with daily usual folic acid intake $\geq 400 \mu \mathrm{g}$

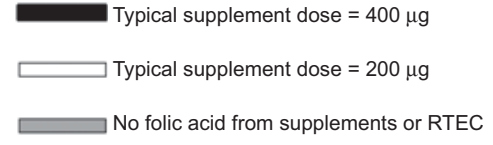

Relative size of marker indicates RTEC fortification level $(400 \mu \mathrm{g}, 200 \mu \mathrm{g}, 100 \mu \mathrm{g} / \mathrm{serving})$

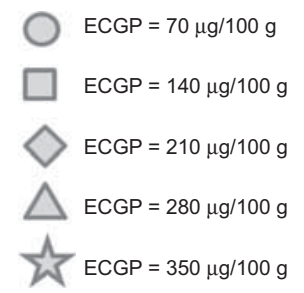

Fig. 3 Percentage of US non-pregnant women of childbearing age (15 to 44 years) with usual daily folic acid intake $\geq 400 \mu g$ and percentage of adults (age 19 years and older) with usual folic acid intake $>1000 \mu \mathrm{g}$ under different fortification and supplementation scenarios, National Health and Nutrition Examination Survey, 2003-2008 (ECGP, enriched cereal grain product; RTEC, ready-to-eat cereal)

consumers at the high end of the distribution rather than the low end. This is because individuals with high consumption of folic acid are also the most likely to consume RTEC and supplements ${ }^{(24,25)}$.

Our modelling exercise also illustrates the importance of considering subpopulations when assessing various folic acid fortification scenarios. While goals could be set at a national level, our results indicate that approaches targeted to specific racial/ethnic groups might be needed for subpopulations. For example, other modelling exercises have looked at the potential impact of fortifying corn masa flour with folic acid in an attempt to selectively increase intake among Mexican Americans ${ }^{(26)}$.

Although current recommendations exist for the global fortification of flour with folic acid(27), it is also recommended that countries consider the dietary patterns of their population ${ }^{(28)}$. Modelling usual intake under different fortification scenarios can provide valuable information in the development of fortification policies. Although we used six years of US nationally representative data on dietary intake, data of this level of sophistication are not necessary for using the principles of modelling to inform decisions regarding fortification in other countries. Modelling can be useful even for countries with only one primary source of folic acid, and for countries attempting to identify which product or products to fortify and at what level. For example, ECGP are relatively self-limiting in terms of the maximum amount that a typical person would eat in one day (e.g. an adult who consumed only ECGP fortified at $140 \mu \mathrm{g}$ would have to consume more than $680 \mathrm{~g}(1.5 \mathrm{lb})$ of ECGP daily to exceed the UL of $1000 \mu \mathrm{g})$. However, other potential fortification vehicles, such as RTEC, could have greater potential to be consumed in quantities higher than intended. With no folic acid in RTEC or supplements (i.e. G scenarios), which approximates the current situation in the developing world, the highest level of fortification in our model $(350 \mu \mathrm{g} / 100 \mathrm{~g})$ resulted in $18 \%$ of women of childbearing age consuming at least the recommended $400 \mu \mathrm{g} / \mathrm{d}$ with virtually no adults whose intake exceeded the UL. 
Table 4 Percentage of US non-pregnant women of childbearing age ( 15 to 44 years) with usual daily intake of folic acid $\geq 400 \mu \mathrm{g}$ and percentage of adults (age 19 years and older) with usual daily intake of folic acid $>1000 \mu \mathrm{g}$ under various fortification and supplementation scenarios, National Health and Nutrition Examination Survey, 2003-2008, by race and ethnicity

\begin{tabular}{|c|c|c|c|c|c|c|c|c|c|c|c|c|}
\hline \multirow[b]{2}{*}{ Scenario } & \multicolumn{4}{|c|}{ Non-Hispanic white } & \multicolumn{4}{|c|}{ Non-Hispanic black } & \multicolumn{4}{|c|}{ Mexican-American } \\
\hline & $\begin{array}{l}\% \text { of WCBA } \\
\geq 400 \mu \mathrm{g} / \mathrm{d}\end{array}$ & $95 \% \mathrm{Cl}$ & $\begin{array}{l}\% \text { of adults } \\
>1000 \mu \mathrm{g} / \mathrm{d}\end{array}$ & $95 \% \mathrm{Cl}$ & $\begin{array}{c}\% \text { of WCBA } \\
\geq 400 \mu \mathrm{g} / \mathrm{d}\end{array}$ & $95 \% \mathrm{Cl}$ & $\begin{array}{l}\% \text { of adults } \\
>1000 \mu \mathrm{g} / \mathrm{d}\end{array}$ & $95 \% \mathrm{Cl}$ & $\begin{array}{l}\% \text { of WCBA } \\
\geq 400 \mu \mathrm{g} / \mathrm{d}\end{array}$ & $95 \% \mathrm{Cl}$ & $\begin{array}{l}\% \text { of adults } \\
>1000 \mu \mathrm{g} / \mathrm{d}\end{array}$ & $95 \% \mathrm{Cl}$ \\
\hline \multicolumn{13}{|c|}{ Changing mandatory ECGP and maximum voluntary RTEC fortification levels (no change to supplement amounts) } \\
\hline A70 & $23 \cdot 3$ & $20 \cdot 6,26 \cdot 0^{*}$ & $2 \cdot 8$ & $2 \cdot 3,3 \cdot 3^{*}$ & 5.3 & $2 \cdot 6,8 \cdot 0$ & 0.5 & $0.2,0.7$ & $7 \cdot 9$ & $4 \cdot 8,11 \cdot 1$ & 0.4 & $0.2,0.7$ \\
\hline A140 & $29 \cdot 3$ & $26 \cdot 6,32 \cdot 0^{\star}$ & 3.5 & $2 \cdot 9,4 \cdot 2^{\star}$ & $8 \cdot 7$ & $5 \cdot 2,12 \cdot 3$ & 0.6 & $0.3,0.9$ & $12 \cdot 4$ & $8 \cdot 6,16 \cdot 2$ & 0.6 & $0.3,0.9$ \\
\hline A210 & $38 \cdot 6$ & $36 \cdot 0,41 \cdot 2^{\star}$ & $4 \cdot 6$ & $3 \cdot 8,5 \cdot 3^{*}$ & $16 \cdot 1$ & $11 \cdot 7,20 \cdot 5$ & 0.9 & $0 \cdot 4,1 \cdot 3$ & $20 \cdot 8$ & $16 \cdot 6,25 \cdot 1$ & 0.9 & $0 \cdot 4,1 \cdot 3$ \\
\hline A280 & $48 \cdot 7$ & $46 \cdot 2,51 \cdot 3^{\star}$ & $6 \cdot 2$ & $5 \cdot 3,7 \cdot 1^{*}$ & $27 \cdot 4$ & $22 \cdot 8,31 \cdot 9$ & $1 \cdot 4$ & $0 \cdot 8,2 \cdot 0$ & $32 \cdot 1$ & $28 \cdot 0,36 \cdot 2$ & 1.5 & $0 \cdot 8,2 \cdot 3$ \\
\hline A350 & $58 \cdot 9$ & $56 \cdot 2,61 \cdot 6^{\star}$ & $8 \cdot 6$ & $7 \cdot 5,9 \cdot 7^{\star}$ & $40 \cdot 3$ & $36 \cdot 2,44 \cdot 3$ & $2 \cdot 3$ & $1 \cdot 4,3 \cdot 3$ & $44 \cdot 8$ & $41 \cdot 1,48 \cdot 6$ & $2 \cdot 8$ & $1 \cdot 6,4 \cdot 0$ \\
\hline B70 & $21 \cdot 5$ & $18 \cdot 9,24 \cdot 1^{*}$ & $2 \cdot 2$ & $1 \cdot 8,2 \cdot 7^{*}$ & $4 \cdot 7$ & $2 \cdot 3,7 \cdot 1$ & 0.3 & $0.1,0.5$ & $6 \cdot 9$ & $4 \cdot 0,9 \cdot 8$ & 0.3 & $0 \cdot 1,0.5$ \\
\hline B140 & $27 \cdot 6$ & $25 \cdot 0,30 \cdot 3^{\star}$ & $2 \cdot 9$ & $2 \cdot 4,3 \cdot 4^{\star}$ & $8 \cdot 3$ & $5 \cdot 0,11 \cdot 6$ & 0.5 & $0.2,0.8$ & $11 \cdot 3$ & $7 \cdot 7,14 \cdot 9$ & 0.5 & $0.2,0.8$ \\
\hline B210 & $36 \cdot 8$ & $34 \cdot 2,39 \cdot 4^{\star}$ & $3 \cdot 9$ & $3 \cdot 3,4 \cdot 6^{\star}$ & $15 \cdot 3$ & $11 \cdot 1,19 \cdot 5$ & $0 \cdot 7$ & $0 \cdot 3,1 \cdot 0$ & $19 \cdot 4$ & $15 \cdot 3,23 \cdot 6$ & $0 \cdot 7$ & $0 \cdot 3,1 \cdot 1$ \\
\hline B280 & $47 \cdot 0$ & $44 \cdot 5,49 \cdot 6^{\star}$ & $5 \cdot 5$ & $4 \cdot 6,6 \cdot 3^{*}$ & $26 \cdot 3$ & $21 \cdot 9,30 \cdot 8$ & $1 \cdot 1$ & $0 \cdot 6,1 \cdot 7$ & $30 \cdot 6$ & $26 \cdot 5,34 \cdot 7$ & $1 \cdot 4$ & $0 \cdot 7,2 \cdot 0$ \\
\hline B350 & $57 \cdot 3$ & $54 \cdot 6,59 \cdot 9^{*}$ & $7 \cdot 8$ & $6 \cdot 7,8 \cdot 8^{*}$ & 39.5 & $35 \cdot 4,43 \cdot 5$ & $2 \cdot 0$ & $1 \cdot 2,2 \cdot 9$ & 43.5 & $39 \cdot 8,47 \cdot 3$ & $2 \cdot 5$ & $1 \cdot 4,3 \cdot 6$ \\
\hline C70 & $19 \cdot 1$ & $16 \cdot 6,21 \cdot 6^{*}$ & $1 \cdot 9$ & $1 \cdot 5,2 \cdot 3^{*}$ & $4 \cdot 2$ & $2 \cdot 0,6 \cdot 4$ & 0.3 & $0.1,0.4$ & $5 \cdot 4$ & $2 \cdot 9,7 \cdot 8$ & 0.3 & $0.1,0.4$ \\
\hline C140 & $24 \cdot 8$ & $22 \cdot 2,27 \cdot 4^{\star}$ & $2 \cdot 5$ & $2 \cdot 0,3 \cdot 0^{*}$ & $7 \cdot 5$ & $4 \cdot 5,10 \cdot 6$ & 0.4 & $0.2,0.6$ & $9 \cdot 2$ & $5 \cdot 9,12 \cdot 4$ & 0.4 & $0.2,0.6$ \\
\hline C210 & $33 \cdot 9$ & $31 \cdot 3,36 \cdot 5^{\star}$ & $3 \cdot 4$ & $2 \cdot 8,4 \cdot 0^{*}$ & $14 \cdot 2$ & $10 \cdot 2,18 \cdot 2$ & $0 \cdot 6$ & $0.3,0.9$ & $16 \cdot 6$ & $12 \cdot 6,20 \cdot 6$ & 0.6 & $0 \cdot 3,1 \cdot 0$ \\
\hline C280 & $44 \cdot 1$ & $41 \cdot 6,46 \cdot 6^{\star}$ & $4 \cdot 8$ & $4 \cdot 0,5 \cdot 6^{*}$ & $25 \cdot 0$ & $20 \cdot 7,29 \cdot 4$ & $1 \cdot 0$ & $0.5,1.5$ & $27 \cdot 4$ & $23 \cdot 2,31 \cdot 6$ & $1 \cdot 2$ & $0 \cdot 6,1 \cdot 8$ \\
\hline C350 & $54 \cdot 5$ & $51 \cdot 9,57 \cdot 1^{\star}$ & $6 \cdot 9$ & $5 \cdot 9,7 \cdot 9^{*}$ & $38 \cdot 1$ & $34 \cdot 1,42 \cdot 1$ & $1 \cdot 8$ & $1 \cdot 0,2 \cdot 6$ & $40 \cdot 4$ & $36 \cdot 6,44 \cdot 2$ & $2 \cdot 3$ & $1 \cdot 2,3 \cdot 3$ \\
\hline \multicolumn{13}{|c|}{ Changing mandatory ECGP and maximum voluntary RTEC fortification levels and decreasing the usual folic acid amount in dietary supplements } \\
\hline D70 & 13.9 & $11 \cdot 2,16 \cdot 6^{\star}$ & $1 \cdot 2$ & $0.9,1 \cdot 5^{\star}$ & $2 \cdot 8$ & $0 \cdot 7,4 \cdot 8$ & 0.2 & $0 \cdot 1,0 \cdot 4$ & $5 \cdot 5$ & $2 \cdot 7,8 \cdot 2$ & 0.2 & $0 \cdot 1,0 \cdot 4$ \\
\hline D140 & $20 \cdot 6$ & $17 \cdot 6,23 \cdot 6^{\star}$ & $1 \cdot 4$ & $1 \cdot 0,1 \cdot 8^{*}$ & $5 \cdot 5$ & $2 \cdot 3,8 \cdot 7 \dagger$ & $0 \cdot 3$ & $0.1,0.4$ & $9 \cdot 7$ & $6 \cdot 0,13 \cdot 4$ & 0.3 & $0.1,0.5$ \\
\hline D210 & $30 \cdot 5$ & $27 \cdot 5,33 \cdot 5^{\star}$ & $1 \cdot 7$ & $1 \cdot 2,2 \cdot 1^{*}$ & $11 \cdot 4$ & $6 \cdot 8,15 \cdot 9+$ & 0.4 & $0.1,0.6$ & $17 \cdot 3$ & $12 \cdot 9,21 \cdot 7$ & 0.4 & $0.1,0.8$ \\
\hline D280 & $41 \cdot 9$ & $39 \cdot 1,44 \cdot 8^{\star}$ & $2 \cdot 7$ & $2 \cdot 0,3 \cdot 3^{*}$ & $22 \cdot 1$ & $16 \cdot 8,27 \cdot 3+$ & 0.6 & $0 \cdot 2,1 \cdot 0$ & $29 \cdot 1$ & $24 \cdot 7,33 \cdot 6$ & $0 \cdot 8$ & $0 \cdot 2,1 \cdot 3$ \\
\hline D350 & $53 \cdot 8$ & $50 \cdot 9,56 \cdot 6^{\star}$ & $4 \cdot 1$ & $3 \cdot 2,5 \cdot 0^{*}$ & $35 \cdot 8$ & $31 \cdot 1,40 \cdot 4 t$ & $1 \cdot 1$ & $0 \cdot 5,1 \cdot 8$ & $42 \cdot 3$ & $38 \cdot 4,46 \cdot 3$ & 1.5 & $0 \cdot 6,2 \cdot 4$ \\
\hline E70 & $12 \cdot 2$ & $9 \cdot 7,14 \cdot 7^{\star}$ & 0.9 & $0 \cdot 7,1 \cdot 1^{*}$ & $2 \cdot 3$ & $0.5,4.0$ & 0.2 & $0.04,0.3$ & $4 \cdot 6$ & $2 \cdot 1,7 \cdot 1$ & 0.2 & $0.04,0.3$ \\
\hline E140 & $18 \cdot 7$ & $15 \cdot 8,21 \cdot 5^{\star}$ & $1 \cdot 1$ & $0 \cdot 8,1 \cdot 4^{*}$ & $4 \cdot 3$ & $1 \cdot 6,7 \cdot 0+$ & 0.2 & $0.1,0.3$ & $8 \cdot 5$ & $5 \cdot 1,12 \cdot 0$ & 0.2 & $0 \cdot 1,0 \cdot 4$ \\
\hline E210 & $28 \cdot 3$ & $25 \cdot 4,31 \cdot 3^{\star}$ & 1.5 & $1 \cdot 1,1 \cdot 9^{*}$ & $10 \cdot 3$ & $6 \cdot 1,14 \cdot 6+$ & $0 \cdot 3$ & $0.1,0.4$ & $16 \cdot 0$ & $11 \cdot 7,20 \cdot 3$ & 0.3 & $0.1,0.5$ \\
\hline E280 & $39 \cdot 9$ & $37 \cdot 1,42 \cdot 7^{\star}$ & $2 \cdot 2$ & $1 \cdot 6,2 \cdot 8^{\star}$ & $20 \cdot 7$ & $15 \cdot 6,25 \cdot 8 \dagger$ & 0.5 & $0 \cdot 1,0.8$ & $27 \cdot 6$ & $23 \cdot 2,32 \cdot 0$ & 0.6 & $0 \cdot 2,1 \cdot 1$ \\
\hline E350 & $51 \cdot 9$ & $49 \cdot 1,54 \cdot 7^{\star}$ & 3.5 & $2 \cdot 7,4 \cdot 3^{*}$ & $34 \cdot 8$ & $30 \cdot 2,39 \cdot 4 t$ & 0.9 & $0 \cdot 3,1 \cdot 4$ & $40 \cdot 9$ & $37 \cdot 0,44 \cdot 9$ & $1 \cdot 3$ & $0.5,2 \cdot 2$ \\
\hline F70 & $10 \cdot 1$ & $7 \cdot 8,12 \cdot 3^{*}$ & $0 \cdot 8$ & $0 \cdot 6,1 \cdot 0^{*}$ & $1 \cdot 8$ & $0.4,3.3$ & $0 \cdot 1$ & $0.04,0.2$ & $3 \cdot 3$ & $1 \cdot 4,5 \cdot 3$ & $0 \cdot 1$ & $0.03,0.3$ \\
\hline $\mathrm{F} 140$ & $15 \cdot 9$ & $13 \cdot 2,18 \cdot 6^{\star}$ & 0.9 & $0 \cdot 7,1 \cdot 2^{*}$ & $3 \cdot 8$ & $1 \cdot 4,6 \cdot 2$ & 0.2 & $0.04,0.3$ & $6 \cdot 4$ & $3 \cdot 5,9 \cdot 3$ & 0.2 & $0.04,0.3$ \\
\hline F210 & $25 \cdot 1$ & $22 \cdot 2,28 \cdot 0^{\star}$ & $1 \cdot 2$ & $0.9,1.5^{*}$ & $9 \cdot 2$ & $5 \cdot 2,13 \cdot 1$ & 0.2 & $0.1,0.4$ & $13 \cdot 1$ & $9 \cdot 0,17 \cdot 1$ & 0.3 & $0.1,0.5$ \\
\hline F280 & $36 \cdot 6$ & $33 \cdot 7,39 \cdot 5^{\star}$ & $1 \cdot 8$ & $1 \cdot 3,2 \cdot 3^{*}$ & $19 \cdot 3$ & $14 \cdot 4,24 \cdot 3$ & 0.4 & $0.1,0.7$ & $24 \cdot 2$ & $19 \cdot 7,28 \cdot 7$ & 0.5 & $0.2,0.9$ \\
\hline F350 & $48 \cdot 9$ & $46 \cdot 2,51 \cdot 7^{\star}$ & $3 \cdot 0$ & $2 \cdot 3,3 \cdot 7^{\star}$ & $33 \cdot 4$ & $28 \cdot 8,38 \cdot 0$ & 0.8 & $0 \cdot 3,1 \cdot 3$ & $37 \cdot 6$ & $33 \cdot 5,41 \cdot 7$ & $1 \cdot 2$ & $0.4,1.9$ \\
\hline \multicolumn{13}{|c|}{ Changing mandatory ECGP levels with no folic acid fortification of RTEC and no folic acid from dietary supplements } \\
\hline G70 & 0 & & 0 & & 0 & & 0 & & 0 & & 0 & \\
\hline G140 & 0 & & 0 & & 0 & & 0 & & 0 & & 0 & \\
\hline G210 & 0.4 & $0,1 \cdot 3$ & 0 & & $0 \cdot 2$ & $0,0 \cdot 6$ & 0 & & 0.5 & $0,1 \cdot 4$ & 0 & \\
\hline G280 & $5 \cdot 2$ & $1 \cdot 3,9 \cdot 1$ & 0 & & $3 \cdot 0$ & $0,6 \cdot 6$ & 0 & & $5 \cdot 0$ & $0.4,9.6$ & 0 & \\
\hline G350 & $18 \cdot 0$ & $12 \cdot 2,23 \cdot 9$ & 0 & & $13 \cdot 6$ & $6 \cdot 7,20 \cdot 5$ & 0 & & $16 \cdot 9$ & $9 \cdot 9,23 \cdot 9$ & 0 & \\
\hline
\end{tabular}

WCBA, women of childbearing age; ECGP, enriched cereal grain product; RTEC, ready-to-eat cereal.

Italics indicates current fortification/supplementation scenario; see Table 1 for details of others.

All $P$ values are from $\chi^{2}$ tests.

*Statistically significantly $(P<0.05)$ different from non-Hispanic blacks and Mexican Americans.

tStatistically significantly $(P<0.05)$ different from Mexican Americans. 
Therefore countries with no other sources of folic acid might decide to fortify at a higher level than the USA, such as was done in Chile, which chose to fortify ECGP at a level of $220 \mu \mathrm{g} / 100 \mathrm{~g}$.

Strengths of our modelling exercise include the use of a large, nationally representative sample of US adults and the ability to examine differences by race and ethnicity due to oversampling. The addition of folic acid to the nutrient database and the ability to take into account dayto-day variation allowed us to make more precise estimates than were possible in the past. The estimates in the current report are subject to several limitations. Actual folic acid in foods might be higher or lower than that estimated in the nutrient database ${ }^{(13)}$. The amount of folic acid indicated on supplement labels could be an underestimate $^{(29)}$. Dietary data are self-reported. It has been previously reported that the $24 \mathrm{~h}$ dietary recall used in NHANES underestimates energy intake by $11 \%$, but how this translates to estimates of micronutrient intake such as folic acid is unclear ${ }^{(30,31)}$.

Our modelling assumes that the dietary patterns of the population that consumes products that contain folic acid would not change if the folic acid content of the product was changed. It is also probable that the number of products voluntarily fortified with folic acid will change over time. Therefore, the actual impact of any changes in fortification is difficult to predict.

Our results demonstrate the value of considering the contribution of all folic acid sources among population subgroups when assessing the implications of policies and initiatives to increase folic acid consumption. Public health efforts should continue to increase consumption of folic acid among women of childbearing potential and thereby reduce the prevalence of NTD.

\section{Acknowledgements}

The research was funded by the US Centers for Disease Control and Prevention. The findings and conclusions in this report are those of the authors and do not necessarily represent the official position of the Centers for Disease Control and Prevention. The authors report no conflicts of interest. Each author contributed to the development of this work. S.C.T., M.E.C., H.C.H. and R.J.B. designed the research; S.C.T. analysed the data and performed statistical analysis; S.C.T., M.E.C., H.C.H. and R.J.B. wrote the paper. S.C.T. had primary responsibility for final content. The authors would like to gratefully acknowledge Alicia Carriquiry for her assistance in using PC-SIDE to estimate usual intake.

\section{Supplementary materials}

For Supplementary materials for this article, please visit http://dx.doi.org/10.1017/S1368980012000638

\section{References}

1. Czeizel AE \& Dudas I (1992) Prevention of the first occurrence of neural-tube defects by periconceptional vitamin supplementation. $N$ Engl J Med 327, 1832-1835.

2. MRC Vitamin Study Research Group (1991) Prevention of neural tube defects: results of the Medical Research Council Vitamin Study. MRC Vitamin Study Research Group. Lancet 338, 131-137.

3. Centers for Disease Control and Prevention (1992) Recommendations for the use of folic acid to reduce the number of cases of spina bifida and other neural tube defects. MMWR Recomm Rep 41, 1-7.

4. Food and Drug Administration (1993) Food labeling: health claims and label statement; folate and neural tube defects. Federal Register 58, 53254-53295.

5. Food and Drug Administration (1996) Food standards: amendment of standards of identity for enriched grain products to require addition of folic acid, Final Rule. 21 CFR Parts 136, 137, and 139. Federal Register 64, 8781-8797.

6. Institute of Medicine (1998) DRI Dietary Reference Intakes for Thiamin, Riboflavin, Niacin, Vitamin $B_{6}$, Folate, Vitamin $B_{12}$, Pantothenic Acid, Biotin, and Choline. Washington, DC: National Academy Press.

7. Centers for Disease Control and Prevention (2004) Spina bifida and anencephaly before and after folic acid mandate United States, 1995-1996 and 1999-2000. MMWR Morbid Mortal Wkly Rep 53, 362-365.

8. Health Canada (1996) Food and drugs regulations amendment SOR/96-527. Canada Gazette Part II 130, 3318-3320.

9. Chen LT \& Rivera MA (2004) The Costa Rican experience: reduction of neural tube defects following food fortification programs. Nutr Rev 62, 6 Pt 2, S40-S43.

10. Hertrampf E \& Cortes F (2004) Folic acid fortification of wheat flour: Chile. Nutr Rev 62, 6 Pt 2, S44-S48.

11. Sayed AR, Bourne D, Pattinson R et al. (2008) Decline in the prevalence of neural tube defects following folic acid fortification and its cost-benefit in South Africa. Birth Defects Res A Clin Mol Teratol 82, 211-216.

12. Food Standards Australia New Zealand (2006) Final Assessment Report, Proposal P295, Consideration for Mandatory Fortification with Folic Acid. Canberra: FSANZ.

13. Raper N, Perloff B, Ingwersen L et al. (2004) An overview of USDA's dietary intake data system. J Food Compost Anal 17, 545-555.

14. Carriquiry AL (2003) Estimation of usual intake distributions of nutrients and foods. J Nutr 133, issue 2, 601S-608S.

15. National Center for Health Statistics (2005) 2003-2004 National Health and Nutrition Examination Survey (NHANES). http://www.cdc.gov/nchs/nhanes/nhanes20032004/nhanes03_04.htm (accessed October 2011).

16. National Center for Health Statistics (2007) 2005-2006 National Health and Nutrition Examination Survey (NHANES). http://www.cdc.gov/nchs/nhanes/nhanes20052006/nhanes05_06.htm (accessed October 2011).

17. National Center for Health Statistics (2009) 2007-2008 National Health and Nutrition Examination Survey (NHANES). Available at http://www.cdc.gov/nchs/nhanes/nhanes2007-2008/ nhanes07_08.htm (accessed October 2011).

18. Food and Drug Administration (1996) Food additives permitted for direct addition to food for human consumption; folic acid (folacin), final rule. Federal Register 64, $8797-8807$.

19. US Department of Agriculture (2006) USDA Food and Nutrient Database for Dietary Studies, 2.0. Beltsville, MD: Agricultural Research Service, Food Surveys Research Group; available at http://www.ars.usda.gov/Services/docs. htm?docid $=12083$ 
20. US Department of Agriculture (2008) USDA Food and Nutrient Database for Dietary Studies, 3.O. Beltsville, MD: Agricultural Research Service, Food Surveys Research Group; available at http://www.ars.usda.gov/Services/docs.htm?docid=17031

21. Nusser S, Carriquiry A, Dodd KW et al. (1996) A semiparametric transformation approach to estimating usual nutrient intake distributions. I Am Stat Assoc 91, 1440-1449.

22. Crane NT, Wilson DB, Cook DA et al. (1995) Evaluating food fortification options: general principles revisited with folic acid. Am J Public Health 85, 660-666.

23. US Preventive Services Task Force (2009) Folic acid for the prevention of neural tube defects: US Preventive Services Task Force recommendation statement. Ann Intern Med 150, 626-631.

24. Tinker SC, Cogswell ME, Devine O et al. (2010) Folic acid intake among US women aged 15-44 years, National Health and Nutrition Examination Survey, 2003-2006. Am J Prev Med 38, 534-542.

25. Yang Q, Cogswell ME, Hamner HC et al. (2010) Folic acid source, usual intake, and folate and vitamin B-12 status in US adults: National Health and Nutrition Examination Survey (NHANES) 2003-2006. Am J Clin Nutr 91, 64-72.

26. Hamner HC, Mulinare J, Cogswell ME et al. (2009) Predicted contribution of folic acid fortification of corn masa flour to the usual folic acid intake for the US population: National Health and Nutrition Examination Survey 2001-2004. Am J Clin Nutr 89, 305-315.

27. World Health Organization, Food and Agriculture Organization of the United Nations, UNICEF, GAIN, Micronutrient Initiative \& Flour Fortification Initiative (2009) Recommendations on Wheat and Maize Flour Fortification. Meeting Report: Interim Consensus Statement. Geneva: WHO.

28. World Health Organization (2009) WHO Meeting on Estimating the Appropriate Levels of Vitamins and Minerals for Food Fortification Programmes: The WHO Intake Monitoring, Assessment and Planning Program (IMAPP). Geneva: WHO.

29. US Department of Agriculture (2009) USDA Dietary Supplement Ingredient Database; Release 1. Beltsville, MD: USDA.

30. Centers for Disease Control and Prevention (1994) Daily dietary fat and total food-energy intakes - Third National Health and Nutrition Examination Survey, Phase 1, 1988-91. MMWR Weekly Rep 43, 116-125.

31. Moshfegh AJ, Rhodes DG, Baer DJ et al. (2008) The US Department of Agriculture Automated Mulitple-Pass Method reduces bias in the collection of energy intakes. Am J Clin Nutr 88, 324-332. 